\title{
Efficiency of essential oils of Ocimum basilicum and Cymbopogum flexuosus in the sedation and anaesthesia of Nile tilapia juveniles
}

\author{
JOSÉ D. LIMMA NETTO, REBECA S.M. OLIVEIRA and CARLOS EDUARDO COPATTI \\ Instituto de Biologia, Universidade Federal da Bahia, Rua Barão de Geremoabo, \\ 147, Campus Ondina, 40170-290 Salvador, BA, Brazil
}

Manuscript received on January 2, 2017; accepted for publication on February 9, 2017

\begin{abstract}
This study aimed to verify the sedative and anaesthetic effect of the essential oils of basil (Ocimum basilicum) (EOOB) and lemongrass (Cymbopogum flexuosus) (EOCF) in Nile tilapia juveniles. The fish were transferred to aquaria containing different concentrations of each essential oil: 10, 25, 50, 100, 200, 400 and $600 \mu \mathrm{L} \mathrm{L}^{-1}$. The time of sedation ranged from 7 to 31 seconds and the recommended concentration was 10 or $25 \mu \mathrm{L} \mathrm{L}^{-1}$ for both essential oils. The best times for anaesthesia and recovery were found for the concentrations of $400 \mu \mathrm{L} \mathrm{L}^{-1}$ for EOOB (135.2 and 199.1 seconds, respectively) and $600 \mu \mathrm{L} \mathrm{L}^{-1}$ for EOCF (327.1 and 374.8 seconds, respectively). In conclusion, we recommend the use of EOOB and EOCF for the sedation and anaesthesia of Nile tilapia at concentrations of 10-25 (for both), 400 and $600 \mu \mathrm{L} \mathrm{L}^{-1}$, respectively.
\end{abstract}

Key words: sedation, recovery, basil, lemongrass.

\section{INTRODUCTION}

Practices carried out in aquaculture such as handling and transport expose fish to stress, reduce feeding and increase susceptibility to diseases (Limma-Netto et al. 2016, Teixeira et al. 2017). Anaesthetics are commonly used to facilitate handling and transport, and they can reduce or mitigate stress in fish. Essential oils derived from different plant species have been used as sedatives and anaesthetics in fish (Sena et al. 2016, Teixeira et al. 2017).

The essential oils of basil (Ocimum basilicum) (EOOB) and lemongrass (Cymbopogon flexuosus)

Correspondence to: Carlos Eduardo Copatti

E-mail: carloseduardocopatti@yahoo.com.br
(EOCF) are natural products and have already been verified as sedatives and anaesthetics in silver catfish (Rhamdia quelen) (dos Santos et al. 2017) and tambacu (Limma-Netto et al. 2016). Nile tilapia (Oreochromis niloticus) adapts easily to different environments and is one of the most important species of freshwater fish for global aquaculture. In this sense, the present proposal aims to verify the sedative and anaesthetic effect of EOOB and EOCF in Nile tilapia juveniles.

\section{MATERIALS AND METHODS}

Essential oils were obtained from the Pólo de Tecnologia da Unijuí, Três Passos-RS. The essential oils were extracted from dried and 
fresh leaves by drag steam distillation for two hours using a Clevenger-type apparatus. Linalool $(53.35 \%)$ was the major component of EOOB and Geranial $(50.13 \%)$ and Neral $(40.32 \%)$ were the major chemical constituents of the EOCF (LimmaNetto et al. 2016). The experiments were conducted in accordance with the Ethical Committee of the Biology Institute Universidade Federal da Bahia (UFBA) (number 22/2015).

Nile tilapia juveniles $(n=72)$ were purchased from a fish culture and transported to the Laboratório de Sanidade de Organismos Aquáticos at the UFBA. The fish $(17.45 \pm 0.66 \mathrm{~g} ; 10.32 \pm$ $0.19 \mathrm{~cm}$ ) were housed for 10 days in continuously aerated $250 \mathrm{~L}$ tanks with $70 \%$ water exchange every 3 days and fed twice per day with commercial feed. Individuals were fasted for a period of $24 \mathrm{~h}$ prior to the experiments. During the experiments, water quality parameters were maintained at $24^{\circ} \mathrm{C}, \mathrm{pH}$ 7.2, $0.02 \mathrm{mg} \mathrm{L}^{-1}$ un-ionised ammonia and dissolved oxygen concentration above $6.5 \mathrm{mg} \mathrm{L}^{-1}$.

The procedure involved the transfer of juveniles to aquaria containing 2-L of water and $\mathrm{EOOB}$ or EOCF at concentrations of 10, 25, 50, 100, 200, 400 or $600 \mu \mathrm{L} \mathrm{L}^{-1}$ diluted 1:10 with ethanol $(\mathrm{n}=$ 8 each concentration). The ethanol group $(n=8)$ was transferred to aquaria containing $5,400 \mu \mathrm{L} \mathrm{L}^{-1}$ ethanol, which is a concentration equivalent to the dilution used for the highest concentration $(600 \mu \mathrm{L}$ $\left.\mathrm{L}^{-1}\right)$. The control group $(\mathrm{n}=8)$ was transferred to an aquarium containing only water. The times of sedation and anaesthetic induction were evaluated for up to $30 \mathrm{~min}$, and each juvenile was used only once. Then, the juveniles were transferred to an anaesthetic-free aquarium (25-L) to measure the post-anaesthetic recovery time (adapted from Sena et al. 2016).

All data are expressed as the mean \pm SEM and were subjected to the Levene test to verify homogeneity of the variances. The evaluation of sedation time was performed by ANOVA and Tukey's post-hoc tests. A regression analysis of concentration versus anaesthetic induction or recovery time and significance was set at a critical level of $95 \%(\mathrm{P}<0.05)$.

\section{RESULTS}

No mortality was observed. Sedation and anaesthesia were not observed in the ethanol and control groups. EOOB and EOCF were shown to be efficient as sedatives in all concentrations tested. Nile tilapia juveniles recovered immediately after the end of sedation. In general, the sedation time of the concentration $10 \mu \mathrm{L} \mathrm{L}^{-1}$ was significantly higher than the other concentrations $(\mathrm{P}<0.05)$ (Figure 1a and $b$ ).

Anaesthetic induction and recovery times negatively correlated with the EOOB and EOCF concentrations. Anaesthesia was verified from the concentration of $200 \mu \mathrm{L} \mathrm{L}^{-1}$ of EOOB and $100 \mu \mathrm{L}$ $\mathrm{L}^{-1}$ of EOCF. The best times for anaesthesia and recovery were found for the concentrations of $400 \mu \mathrm{L} \mathrm{L}^{-1}$ for EOOB (135.2 and 199.1 seconds, respectively) and $600 \mu \mathrm{L} \mathrm{L}^{-1}$ for EOCF (327.1 and 374.8 seconds, respectively) (Figure 1c, d, e and f).

\section{DISCUSSION}

Anaesthetics at low concentrations have a sedative effect. Sedation is the ideal condition for transport, because the fish keep swimming, but with less vigorous motions, which contributes to reduce metabolism and traumatic lesions (Sena et al. 2016)”ISBN" : “0044-8486", "ISSN”: “00448486”, "PMID" : "222", "abstract" : "Clove oil has become a popular fish anaesthetic for invasive fisheries research procedures, but few studies have examined the use of low concentrations of clove oil to achieve sedation for aquaculture procedures such as fish handling and transport. In this study, we used largemouth bass as a model species to examine the behavioral and physiological responses of fish to a gradation of clove oil concentrations ( 0 to 20 mg $1-1$. Considering that the concentration for 

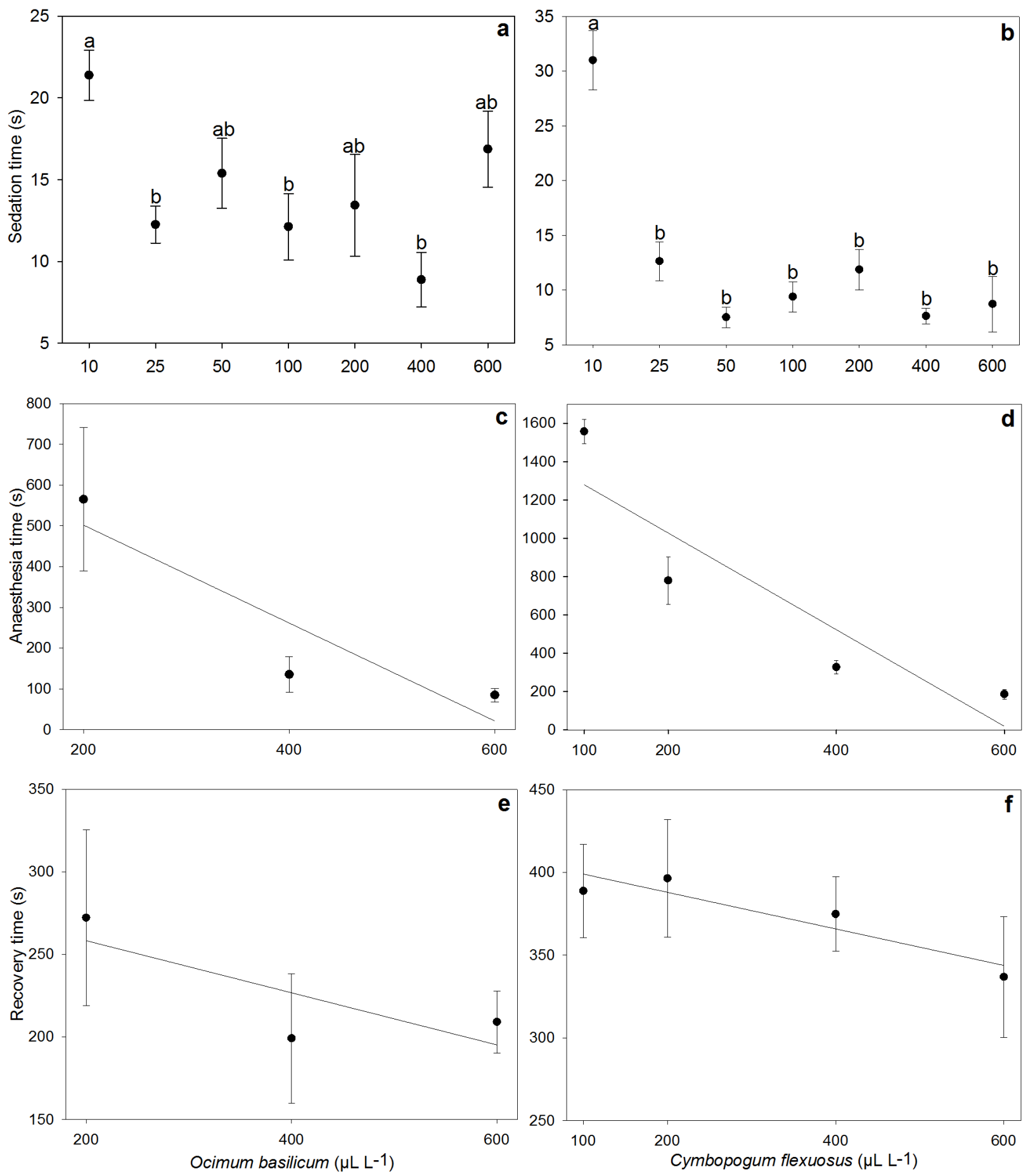

Figure 1 - Time required for the sedation (a and $\mathbf{b})$, induction of anesthesia (c and $\mathbf{d})$ and recovery (e and $\mathbf{f})$ of tambacu using the essential oils of Ocimum basilicum and Cymbopogon flexuosus. a and b: different letters in the column indicate significant difference between concentrations. $\mathbf{c}: \mathrm{y}=741.83-1.20 \mathrm{x} ; \mathrm{r}^{2}=0.83$. $\mathbf{d}: \mathrm{y}=1531.42-2.52 \mathrm{x} ; \mathrm{r}^{2}=0.82$. e: $\mathrm{y}=289.87-0.16 \mathrm{x} ; \mathrm{r}^{2}=0.64$. f: $y=410.03-0.11 x ; r^{2}=0.86$. Where $y=$ Time $(s)$ and $x=$ Essential oil concentration $\left(\mu L^{-1}\right)$. 
sedation should be the minimum possible to avoid anaesthetic induction (Marking and Meyer 1985, Sena et al. 2016), although the fact that the sedation time of the $10 \mu \mathrm{L} \mathrm{L}^{-1}$ concentration was superior to the other concentrations, 10 or $25 \mu \mathrm{L} \mathrm{L}^{-1}$ can be recommended for sedation for both essential oils.

In addition, similar to our observations, the ratio of increased concentration versus reduction of anaesthesia time was verified in previous studies in Nile tilapia with eugenol (Ribeiro et al. 2015) and essential oils of Lippia alba (Hohlenwerger et al. 2016) and Aloysia triphylla (Teixeira et al. 2017). On the other hand, the same studies verified that the anaesthetic recovery time increased with increasing anaesthetic concentration.

Sena et al. (2016) found that the increased anaesthetic concentration of the essential oil of L. alba in tambacu resulted in a reduction in the times for anaesthesia and anaesthetic recovery. In addition, tambacu exposure for EOOB and EOCF resulted in an increase and reduction in anaesthetic recovery time, respectively (Limma-Netto et al. 2016).

In general, according to the previous studies (Ribeiro et al. 2015, Hohlenwerger et al. 2016, Limma-Netto et al. 2016, Teixeira et al. 2017), the recovery time is affected by the increased anaesthetic concentration and is faster at lower concentrations, but this depends on the fish species and the anaesthetic used (as seen by Limma-Netto et al. 2016, Sena et al. 2016). In the present study, we observe that the shortest time of exposure to the anaesthetic has been more determinant than the increase of the anaesthetic concentration to cause a faster recovery after anaesthesia.

\section{CONCLUSIONS}

The use of EOOB and EOCF is efficient and promising for fish farming activities. We recommend the concentrations of $10-25 \mu \mathrm{L} \mathrm{L}^{-1}$ for sedation and 400 and $600 \mu \mathrm{L} \mathrm{L}^{-1}$ of EOOB and EOCF, respectively, for anaesthesia in Nile tilapia juveniles.

\section{REFERENCES}

DOS SANTOS AC, JUNIOR GB, ZAGO DC, ZEPPENFELD CC, DA SILVA DT, HEINZMANN BM, BALDISSEROTTO B AND DA CUNHA MA. 2017. Anesthesia and anesthetic action mechanism of essential oils of Aloysia triphylla and Cymbopogon flexuosus in silver catfish (Rhamdia quelen). Vet Anaesth Analg 44: 106-113.

HOHLENWERGER JC, COPATTI CE, SENA AC, COUTO RD, BALDISSEROTTO B, HEINZMANN BM, CARON BO AND SCHMIDT D. 2016. Could the essential oil of Lippia alba provide a readily available and cost-effective anaesthetic for Nile tilapia (Oreochromis niloticus)? Mar Freshw Behav Phy 49: 119-126.

LIMMA-NETTO JD, SENA AC AND COPATTI CE. 2016. Essential oils of Ocimum basilicum and Cymbopogon flexuosus in the sedation and anesthesia of tambacu. Bol Inst Pesca 42: 727-733.

MARKING LLAND MEYER FP. 1985. Are better anesthetics needed in fisheries? Fisheries, Bethesda 10: 2-5.

RIBEIRO PAP, MIRANDA-FILHO KC, MELO DC AND LUZ RK. 2015 Efficiency of eugenol as anesthetic for the early life stages of Nile tilapia (Oreochromis niloticus). An Acad Bras Cienc 87: 529-535.

SENA AC, TEIXEIRA RR, FERREIRA EL, HEINZMANN BM, BALDISSEROTTO B, CARON BO, SCHMIDT D, COUTO RD AND COPATTI CE. 2016. Essential oil from Lippia alba has anaesthetic activity and is effective in reducing handling and transport stress in tambacu (Piaractus mesopotamicus X Colossoma macropomum). Aquaculture 465: 374-379.

TEIXEIRA RR, DE SOUZA RC, SENA AC, BALDISSEROTTO B, HEINZMANN BM, COUTO RD AND COPATTI CE. 2017. Essential oil of Aloysia triphylla in Nile: anaesthesia, stress parameters and sensory evaluation of fillets. Aquaculture Res 48: 33833392 . 